\title{
"It's Always Good to Ask": A Mixed Methods Study on the Perceived Role of Sexual Health Practitioners Asking Gay and Bisexual Men About Experiences of Domestic Violence and Abuse
}

Journal of Mixed Methods Research 2018, Vol. 12(2) 22I-243 (C) The Author(s) 2016 Reprints and permissions: sagepub.com/journalsPermissions.nav DOI: $10.1177 / 1558689816651808$ journals.sagepub.com/home/mmr

@SAGE

\section{Loraine J. Bacchus', Ana Maria Buller', Giulia Ferrari ${ }^{1,2}$, Petra Brzank ${ }^{3}$, and Gene Feder ${ }^{2}$}

\begin{abstract}
Development of joint displays is a valued approach to merging qualitative and quantitative findings in mixed methods research. This study aimed to illustrate a case series mixed methods display and the utility of using mixed methods for broadening our understanding of domestic violence and abuse. Using a convergent design, 532 gay and bisexual men participated in a Health and Relationship Survey in a U.K. sexual health service and 19 in an interview. Quantitative and qualitative data were analyzed separately and integrated at the level of interpretation and reporting. There were inconsistencies in perceptions and reports of abuse. Men were supportive of selective enquiry for domestic violence and abuse by practitioners $(62.6 \%$; $95 \%$ confidence interval $=58.1 \%$ to $66.7 \%$ ) while being mindful of contextual factors .
\end{abstract}

\section{Keywords}

domestic violence, gay and bisexual men, routine enquiry, mixed methods, sexual health services

Domestic violence and abuse (DVA) is highly prevalent among gay, bisexual, and other men who have sex with men (MSM; Finneran \& Stephenson, 2013). A systematic review reports lifetime prevalence of any type of DVA among MSM to be between $29.7 \%$ and $78.0 \%$ (Finneran \& Stephenson, 2013). DVA in MSM is significantly associated with an increased risk of HIV, depressive symptoms, substance abuse, and unprotected anal sex (Buller, Devries, Howard, \& Bacchus, 2014). Despite the high prevalence and impact on health, their views on the potential role of health care services in supporting those who experience or perpetrate abuse has not been explored.

\footnotetext{
'London School of Hygiene \& Tropical Medicine, London, UK

${ }^{2}$ University of Bristol, Bristol, UK

${ }^{3}$ Technical University Berlin, Berlin, Germany
}

\section{Corresponding Author:}

Loraine J. Bacchus, Faculty of Public Health and Policy, Department of Global Health \& Development, Gender Violence and Health Centre, London School of Hygiene \& Tropical Medicine, 15-17 Tavistock Place, London WCIH 9SE, UK. Email: loraine.bacchus@Ishtm.ac.uk 
In high-income countries, there is evidence that DVA interventions in health care settings can promote positive outcomes for women and that many women find routine enquiry for DVA by health care practitioners acceptable (Feder, Hutson, Ramsay, \& Taket, 2006; Feder et al., 2009). However, there continues to be international debate about a policy of routine enquiry for DVA in health care settings due to insufficient evidence of improved outcomes (Moyer, 2013; O'Doherty et al., 2014; World Health Organization, 2013). The World Health Organization recommends that providers should be trained in how to respond to disclosures of abuse and to be aware of the indicators. However, the U.K. National Institute for Clinical Excellence (2014) guidelines on DVA cite sexual health services as a setting where clinicians should ask service users about DVA as part of routine good clinical practice "even where there are no indicators of such violence and abuse." Furthermore, the guidelines state that practitioners need to be aware of the needs of gay, bisexual, and transsexual people who are at risk of abuse. Public Health England (2015) highlights DVA as a major social determinant of health in gay, bisexual, and other MSM, necessitating further research to improve clinical practice and service provision.

Existing mixed methods studies on DVA tend to report quantitative and qualitative findings separately. There has been little consideration of how meaningful integration could build strong and useful conclusions that are greater than the sum of the individual qualitative and quantitative components. Although mixed methods research has received increasing attention as an important methodology for investigating complex health issues, a review of the quality of mixed methods studies in health service research concluded that integration is not well developed or practiced. Researchers often fail to provide justification for, and transparency of, the mixed methods design. The qualitative components are more likely to be inadequately described, with inferences based disproportionately on one method rather than the findings of all methods (O’Cathain, Murphy, \& Nicholl, 2008).

The development of joint displays has emerged as a highly valued approach for integrating qualitative and quantitative findings in mixed methods research. They facilitate the process of analysis and interpretation and provide a visual representation of mixed method results to generate new inferences (Fetters, Curry, \& Creswell, 2013). There are various approaches to building joint displays, which are usually linked to the type of mixed methods study (Guetterman, Fetters, \& Creswell, 2015). In a convergent design, Dickson, Lee, and Riegel (2011) developed a cross-case comparison of interview data with quantitative scores on measures of self-care, cognitive function, and knowledge in patients with heart failure. This approach enabled them to validate quantitative findings and identify instances of inconsistency. It also provided a fuller understanding of the cognitive influences of self-care. In an exploratory sequential design, Haggerty, Roberge, Freeman, Beaulieu, and Breton (2012) used themes from qualitative studies of patients' views of continuity of care to refine existing instruments. An instrument development joint display mapped the qualitative dimensions of continuity of care to quantitative instrument items. Despite growing interest in joint displays, their use for case study research on DVA is lacking, thereby limiting our understanding of how individuals interpret and respond to abuse items on surveys. Quantitatively assessing the predominant view among men regarding routine enquiry for DVA by health practitioners is important for informing future health care policy. However, this needs to be combined with qualitative data that help clarify the conditions that facilitate their seeking help from health practitioners.

Men are less likely than women to seek help from health professionals for problems such as depression, substance abuse, physical disabilities, and stressful life events (Galdas, Cheater, \& Marshall, 2005). Their reluctance has been linked to internalized gender notions about masculine identity which cause men to be silent about emotional events in their life (Gascoigne \& Whitear, 1999; Möller-Leimkühler, 2002; Moynihan, 1998). A U.K. study of heterosexual men 
attending general practice surgeries found that many expressed difficulty in seeking help from professionals for relationship abuse (Morgan, Williamson, Hester, Jones, \& Feder, 2014). Lesbian, gay, bisexual, and transgender (LGBT) people are often reluctant to seek help from formal services due to fear of homophobic or inappropriate responses from providers (Ball, 2011; Donovan, Hester, Holmes, \& McCarry, 2006; Duke \& Davidson, 2009). Kaschak (2001) refers to the "double closet" that surrounds DVA in same-sex relationships in which victims suffer the dual burden of shame and silence surrounding two highly stigmatized issues, that of being gay (same sex-sexuality) and being abused by a same sex partner.

The reluctance of the LGBT community to seek help can also be understood within historical discourses on DVA. Ball (2011) refers to the binary and heteronormative feminist frameworks that rely on there being a female victim and a male perpetrator. He argues that as a consequence, the LGBT community have no language with which to articulate their experiences. This is echoed in the work of other researchers who have emphasized the powerful role of the "public story about domestic violence" which marginalizes those who are not female victims in a relationship with a male partner (Donovan \& Hester, 2010).

Interventions in health care settings have also been developed within a heteronormative framework and different interventions may be needed for gay and bisexual men. Health practitioners experience multiple challenges when trying to integrate abuse questions into clinical practice with women patients. These include lack of time and confidential space; inadequate training; fear of offending women; feeling frustration when women do not act on advice given; safety concerns and discomfort with asking questions about abuse (Feder et al., 2009). The presence of heterosexism and homophobia within health care settings, combined with health care practitioners' poor understanding of the experiences of LGBT victims of DVA is likely to make their identification and the provision of culturally appropriate services more difficult (Freedburg, 2006).

Case studies outside the field of violence offer important theoretical insights that help broaden our understanding of the factors that inhibit integration of DVA responses into health care delivery. Spector and Pinto (2011) explored the manifestation of culture-based countertransference (i.e., unconscious and/or repressed feelings toward a client) among substance abuse counsellors and how this undermined their efforts to integrate HIV prevention with MSM. They found that substance abuse counsellors were uncomfortable initiating discussions about sexual practices and HIV, and that their heteronormative assumptions and beliefs resulted in missed opportunities for exploring their client's sexual preferences. In another study, the authors used social cognitive theory to explore the extent to which primary care workers in Brazil integrated public health interventions (i.e., referral to drug services) as part of the National Family Health Strategy. Those with higher levels of personal and collective agency were more likely to offer drug use services. This was evidenced in worker's having greater knowledge of current research, evidence-based practice, and the availability of peer support (Spector, Pinto, Rahman, \& de Fonseca, 2015).

In view of the myriad health problems and psychosocial risk behaviors associated with DVA in gay, bisexual, and other MSM (Buller, Devries, et al., 2014) it is imperative that health services acknowledge and address DVA as a potential underlying factor to ensure the delivery of appropriate care. The purpose of this research is to (a) use data from a survey and semistructured interview on gay and bisexual men's experiences of DVA to illustrate a case series mixed methods display and (b) explicate the utility of a mixed methods approach for broadening our understanding of a highly stigmatized and sensitive issue and informing future interventions in sexual health services.

The study is part of PROVIDE, Programme of Research on Violence in Diverse domestic Environments (http://www.bristol.ac.uk/social-community-medicine/projects/provide/) which 
investigated the epidemiology of domestic violence and interventions in a range of health care settings in collaboration with third sector organizations in the United Kingdom.

\section{Methods}

The theoretical orientation underlying the mixed methods approach is pragmatism which rejects paradigm debates and focuses on "what works as the truth regarding the research questions under investigation" (Teddlie \& Tashakkori, 2009). Pragmatists believe that epistemological issues regarding objectivity and subjectivity exist on a continuum, rather than in opposition. Furthermore, they believe that qualitative and quantitative methods are useful and decisions regarding their use should be driven by the research questions. We used a convergent design where qualitative (semistructured interviews) and quantitative (survey) methods were used simultaneously to (a) develop a more comprehensive picture by linking complementary data sources (b) avoid bias intrinsic to single-method approaches, and (c) as a means of compensating specific strengths and weaknesses associated with particular methods (Denscombe, 2008). Combining these methods enabled triangulation, which increased the credibility and validity of the findings, as well as a method for confirming or disconfirming hypotheses (Flick, 2014). Integration occurred through linking the methods of data collection and at the level of interpretation and reporting. At the methods level, integration occurred through connecting, whereby the subsample of men who participated in the semistructured interview were recruited from the population of participants who completed the survey. Integration at the level of interpretation and reporting was achieved by synthesizing qualitative and quantitative data through a narrative approach in the results and discussion using weaving. The results were connected to each other thematically, with qualitative and quantitative data weaving back and forth around the key themes (Fetters et al., 2013).

\section{Health and Relationships Survey}

Between September 2010 and May 2011, an anonymous Health and Relationships Survey was conducted in the waiting rooms of two generic sexual health clinics and one specialist sexual health clinic for LGBT patients in London. The survey took approximately 15 minutes to complete. It elicited demographic information and sexual orientation as well as reported diagnoses of sexually transmitted infections in the past 12 months. Current anxiety and depression were measured with the Hospital Anxiety and Depression Scale (Zigmond \& Snaith, 1983). Alcohol use was measured with the AUDIT-C test (Saunders, Aasland, Babor, de la Fuente, \& Grant, 1993) and illicit drug use was assessed using single-item yes/no questions on past year use of cannabis and class A drugs (Ecstasy, LSD, cocaine, crack, heroin, and injected amphetamines). Men were asked dichotomous "yes" or "no" questions about whether they had experienced or carried out negative and potentially abusive behaviors in the context of an adult intimate relationship including: ever felt frightened of the behavior of a partner; ever needed to ask a partner's permission to work, go shopping, visit relatives or visit friends (beyond being considerate to and checking with a partner); ever been slapped, hit, kicked, or otherwise physically hurt; and ever forced to have sex or made to engage in any sexual activity against one's will. This was followed by questions on whether this had occurred in the past 12 months, relationship with the perpetrator, frequency, escalation, and perceived impact of the abuse. Men were also asked whether they had ever carried out the behaviors toward a current or former partner, whether this occurred in the past 12 months and whether they perceived an effect on their partner. Finally, respondents were asked whether they felt they had been in "domestically violent or abusive relationship" currently and/or in the past. The abuse questions were based on the Comparing 
Heterosexual and Same Sex Abuse in Relationships (COHSAR) survey (Hester, Fahmy, \& Donovan, 2010).

The survey included a question asking respondents if they thought health professionals should ask their patients "whether they have been hurt or frightened by their partner" with response options of "Yes, they should ask all their patients"; "Yes, but they should only ask some of their patients, depending on the symptoms they describe"; and "No, they should not ask any of their patients." Further details of the survey content are published elsewhere (Hester et al., 2015; Williamson et al., 2014). To avoid temporal bias, the clinics were randomized across 28 weeks for survey administration. After registering for a clinic appointment, male patients were invited by a researcher to participate in the survey if they were 18 years or older, attending the clinic alone, and could read and write English. On returning the survey, men were invited to provide contact details if they were willing to take part in an interview at a later date.

\section{Semistructured Interviews}

Men who provided contact details were telephoned by the researchers to explain the purpose of the interview. Semistructured interviews were conducted between October 2010 and May 2011 in a confidential consulting room at the clinic and included questions about completing the clinic survey, experiences and perpetration of potentially abusive behaviors in relationships, experiences of help seeking, and views on enquiry for DVA by sexual health practitioners. Research shows that individuals may report experiencing or carrying out behaviors, but neither consider them harmful nor perceive them as abusive, or only define some types of behaviors as abuse (Hearn, 2013; Hester et al., 2010). Therefore, men were asked about behaviors they experienced from a partner that caused them to feel frightened or unsafe as well as behaviors they had carried out toward a partner that may have caused their partner to feel frightened or unsafe. Probes about specific acts of abuse were used to determine the types of behaviors. Men were asked what they understood by the terms domestic violence and domestic abuse and what types of behaviors they would include in their definition. Following this, they were asked whether or not they would define any of the concerning behaviors they had experienced or carried out as domestic violence or domestic abuse. Further support for this approach to questioning is evidenced in the fact that nearly two thirds of men who reported experiencing at least one negative behavior in the survey, said that they had never been in a domestically violent or abusive relationship in response to the single-item question (Bacchus et al., 2017). Men were asked for their views on enquiry for DVA by health professionals, including the reasons for their preference, how this might be approached in a sexual health clinic, and the potential barriers.

Sampling was opportunistic and the survey results were not used to guide the choice of participants. Interviews were conducted by LJB and AMB, lasted up to 3 hours and were conducted in a private clinic room. To avoid interviewer bias, the researchers were blinded to the participant's survey responses to the items on potentially abusive behaviors and participants were informed of this before the interview commenced. All participants were offered information about support services for men affected by DVA.

\section{Survey Participants}

Of 2,657 men who attended the sexual health clinics during the study period, $1,132(42.4 \%)$ completed a survey. Of the 1,127 men who reported their sexual orientation, $471(41.8 \%)$ were gay, $61(5.4 \%)$ bisexual, and $595(52.8 \%)$ heterosexual. The analysis will focus on the views of $532(47.2 \%)$ gay and bisexual men. 


\section{Semistructured Interview Participants}

Of 47 men who provided their contact details on completion of the survey, 36 had usable telephone numbers and were contacted, of which 24 agreed to be interviewed. Of these, 17 reported their sexuality as gay, 2 bisexual, and 5 heterosexual. Data are presented on 19 gay and bisexual men. Interviews were conducted by two female researchers (LJB and AMB).

\section{Analysis of the Survey Data}

Quantitative data were analyzed in Stata version 12.0 (StataCorp LP, 2011). Descriptive statistics were computed for variables on routine enquiry for DVA by health practitioners. A logistic regression was undertaken to examine factors associated with men's views on routine versus selective enquiry for DVA. The question regarding views on enquiry for DVA by health professionals was transformed to a dichotomous variable indicating whether men favored "routine enquiry of all patients" or "selective enquiry of some patients based on presenting symptoms" as these were the predominant views. Only $14(2.7 \%)$ of men disagreed with any type of enquiry for DVA and they were removed from the analysis to ensure clarity in the dichotomous dependent variable. Furthermore, none of the men who participated in a semistructured interview were opposed to the practice of health practitioners asking men about DVA. For the regression analysis, respondents are men who completed all four survey questions on experiencing negative behavior from a partner and/or all four questions on carrying out negative behaviors. Independent variables included in the regression model were age, ethnicity, maximum level of education attained, employment status, partner status, experiencing a negative behavior from a partner, and carrying out a negative behavior toward a partner. Adjusted odds ratios and $95 \%$ confidence intervals (CIs) are presented.

\section{Analysis of Semistructured Interviews}

Interviews were digitally recorded, transcribed verbatim, and uploaded onto NVivo 10 for organization of the analysis. The initial coding framework was developed in conjunction with colleagues from the wider PROVIDE program following a deductive approach by which the coding tree parents and child nodes mirrored the interview schedule themes. When testing the initial coding framework we allowed for open coding in an inductive process, which allowed new themes to emerge from the data and the subsequent modification of the initial coding framework. After agreeing the final coding framework two researchers, LJB and AMB, coded five transcripts separately. When discrepancies arose, these were discussed as a check for coding consistency (Miles \& Huberman, 1994). When choosing quotes for this article, the authors chose quotes, which represent the views from a wide range of interviewees.

Because of the lack of robust evidence and the small number of bisexual men in both the survey $(n=61)$ and the semistructured interviews $(n=2)$ we chose not to conduct separate analyses for gay and bisexual men. The main nationally representative U.K. survey on DVA, the Crime Survey for England and Wales, has tended to aggregate data on abuse experienced by those identifying as lesbian, gay, or bisexual because of the small numbers. In 2010, they published data on 500 lesbian, gay, and bisexual respondents from the 2007/2008 and 2008/ 2009 domestic violence surveys, and reported higher rates of DVA among this group compared with heterosexual people, although they did not disaggregate data for gay and bisexual men (Donovan \& Hester, 2015). Therefore, it is not known whether the experiences of DVA in gay men are qualitatively different from those of bisexual men. 


\section{Connecting Qualitative and Quantitative Analysis}

Quantitative and qualitative data collection occurred in a parallel and separate manner, but were designed to answer related aspects of the same research questions. We used a parallel mixed data analysis, which involved two separate processes: quantitative analysis of the survey data using descriptive and inferential statistics, and multivariate analysis; and thematic analysis of qualitative data. The two types of analyses were independent, but each contributed to developing a more comprehensive understanding of men's views about enquiry for DVA by health practitioners. Triangulation of the survey and interview data were used to compare how men reported experiences of negative and potentially abusive behavior. We developed a variation of a joint display for case series research in which we present the qualitative accounts of abuse alongside the survey responses for each participant. This provided a visual means to elicit new insights beyond those obtained through separate analysis of these data sources (Guetterman et al., 2015).

\section{Results}

\section{Sociodemographics}

Table 1 presents the sociodemographic characteristics of men who participated in the Health and Relationships Survey and men who participated in the semistructured interviews. Men who participated in the interviews were slightly older, less educated, and predominantly White compared with the survey sample.

\section{Disclosure of Negative and Potentially Abusive Behaviors: Triangulation of Survey and Interview Data}

In the survey, $33.9 \%(95 \% \mathrm{CI}=29.4 \%$ to $37.9 \%)$ reported ever experiencing a negative behavior from a partner; $16.3 \%(95 \% \mathrm{CI}=13.0 \%$ to $19.8 \%)$ reported ever carrying out a negative behavior toward a partner; and $11.4 \%(95 \% \mathrm{CI}=8.7 \%$ to $14.2 \%)$ reported experiencing and carrying out a negative behavior.

Table 2 is a joint display presenting a case comparison of negative and abusive behavior reported by men in the interview and the survey. The display revealed a number of discrepant findings related to underreporting of behaviors experienced and carried out in the survey. For example, in his interview Samuel (56 years) admitted being frightened of his behavior toward his partner, which included throwing objects at him and verbal abuse. His minimization and normalization of these behaviors as "par for the course" and "just aggression in the house" may explain his decision not to report these behaviors on the survey. There was also evidence to support this hypothesis in the survey findings. Of 168 men who reported at least one negative behavior from a partner, $107(63.7 \% ; 95 \% \mathrm{CI}=56.0 \%$ to $70.9 \%)$ said that they had never been in a domestically violent or abusive relationship. Similarly, 57 of $82(69.5 \%$; 95\% CI $=58.8 \%$ to $79.7 \%$ ) who reported carrying out at least one negative behavior toward a partner stated that they had not been in a DVA relationship.

In the interviews some men reported objects being thrown directly at them or around them, verbal abuse and feeling belittled, which negatively affected their emotional well-being. However, these acts were not captured by the four survey items. Lewis (21 years) described feeling jealous and insecure, and constantly required his partner to tell him of his whereabouts, which is a subtle form of controlling behavior. Consequently, his partner would avoid contact with certain friends. However, he did not respond positively to the survey item about requesting 
Table I. Sociodemographics.

\begin{tabular}{|c|c|c|c|c|c|}
\hline \multirow{2}{*}{ Sociodemographics } & \multicolumn{3}{|c|}{$\begin{array}{l}\text { Health and Relationships } \\
\text { Survey }(N=522)\end{array}$} & \multicolumn{2}{|c|}{$\begin{array}{c}\text { Semistructured } \\
\text { interview }(N=19)\end{array}$} \\
\hline & $n$ & Percent & $95 \%$ Confidence interval & $n$ & Percent \\
\hline Mean age (years) & \multicolumn{2}{|l|}{35} & & 39 & \\
\hline Range & & $-75)$ & & \multicolumn{2}{|c|}{$(21-57)$} \\
\hline \multicolumn{6}{|l|}{ Ethnicity } \\
\hline White & 416 & 80.8 & {$[77.1 \%, 84.3 \%]$} & 17 & 89.5 \\
\hline Mixed & 30 & 5.8 & {$[4.0 \%, 8.2 \%]$} & 0 & - \\
\hline Asian/Asian British & 17 & 3.3 & {$[1.8 \%, 5.0 \%]$} & 1 & 5.3 \\
\hline Black/Black British & 27 & 5.2 & {$[3.5 \%, 7.2 \%]$} & 0 & - \\
\hline Other & 25 & 4.9 & {$[2.9 \%, 6.8 \%]$} & 1 & 5.3 \\
\hline \multicolumn{6}{|l|}{ Highest qualification } \\
\hline No education & 12 & 2.3 & {$[1.2 \%, 3.7 \%]$} & 2 & 10.5 \\
\hline GCSE/O Levels $^{a}$ & 32 & 6.2 & {$[4.1 \%, 8.5 \%]$} & 0 & - \\
\hline $\mathrm{NVQ}^{\mathrm{b}}$ & 11 & 2.1 & {$[1.0 \%, 3.6 \%]$} & I & 5.3 \\
\hline A Levels ${ }^{c}$ & 59 & 11.5 & {$[8.4 \%, 14.1 \%]$} & 3 & 15.8 \\
\hline Professional qualification & 41 & 8.0 & {$[5.8 \%, 10.8 \%]$} & 1 & - \\
\hline Bachelor degree & 189 & 36.7 & {$[32.5 \%, 41.0 \%]$} & 6 & 31.6 \\
\hline Postgraduate degree & 17 & 33.3 & {$[29.1 \%, 37.8 \%]$} & 5 & 26.3 \\
\hline \multicolumn{6}{|l|}{ Paid employment } \\
\hline Yes & 464 & 92.4 & {$[90.1 \%, 94.5 \%]$} & 18 & 100.0 \\
\hline No & 38 & 7.6 & {$[5.3 \%, 9.8 \%]$} & 0 & - \\
\hline \multicolumn{6}{|l|}{ Has a current partner ${ }^{d}$} \\
\hline Yes & 244 & 47.3 & {$[43.0,52.1]$} & - & - \\
\hline No & 272 & 52.7 & {$[47.0,57.0]$} & & \\
\hline
\end{tabular}

${ }^{a}$ General Certificate of Secondary Education (GCSE) and Ordinary (O) Level are academic qualifications of U.K. examination boards conferred on students. ${ }^{b}$ National Vocational Qualification (NVQ) is a work-based award in England, Wales, and Northern Ireland achieved through assessment and training. 'Advanced (A) level (General Certificate of Secondary Education A Level) is an academic qualification of U.K. examination boards conferred on students. ${ }^{\mathrm{d}} \mathrm{A}$ specific question on current partner status was not asked in the semistructured interviews. However, men's accounts of DVA included information about whether the abuse pertained to a past or current relationship.

a partner to seek permission. The perceived impact of the abuse may also have influenced whether or not men chose to define their experiences as "abusive" in the survey; for example, in the case of Martin (32 years) who did not feel unsafe or fearful of his partner's behavior.

Some forms of abuse, such as forced sex, may have been too sensitive for men to discuss in a face-to-face interview. Both Nathan (46 years) and Edwin (42 years) disclosed various forms of abuse that they had experienced, but maintained that sexual decision making and negotiation was never an issue in any of their relationships. Yet both of them responded positively to the item on forced sex in the survey, suggesting that the survey method may have been more effective at eliciting disclosure of sexual violence and abuse because it offered anonymity.

\section{Views and Experiences of Routine Versus Selective Enquiry for DVA}

In the Health and Relationships Survey, of 522 gay and bisexual men who responded to the question, $181(34.7 \%$; $95 \% \mathrm{CI}=30.6 \%$ to $39.1 \%)$ felt that health professionals should ask all patients whether they have been hurt or frightened by a partner, $327(62.6 \% ; 95 \% \mathrm{CI}=58.1 \%$ to $66.7 \%)$ only some patients based on symptoms, and $14(2.7 \% ; 95 \% \mathrm{CI}=1.4 \%$ to $4.2 \%)$ stated that health professionals should not ask any patients. Twenty-one out of $523(4.0 \% ; 95 \% \mathrm{CI}=$ 


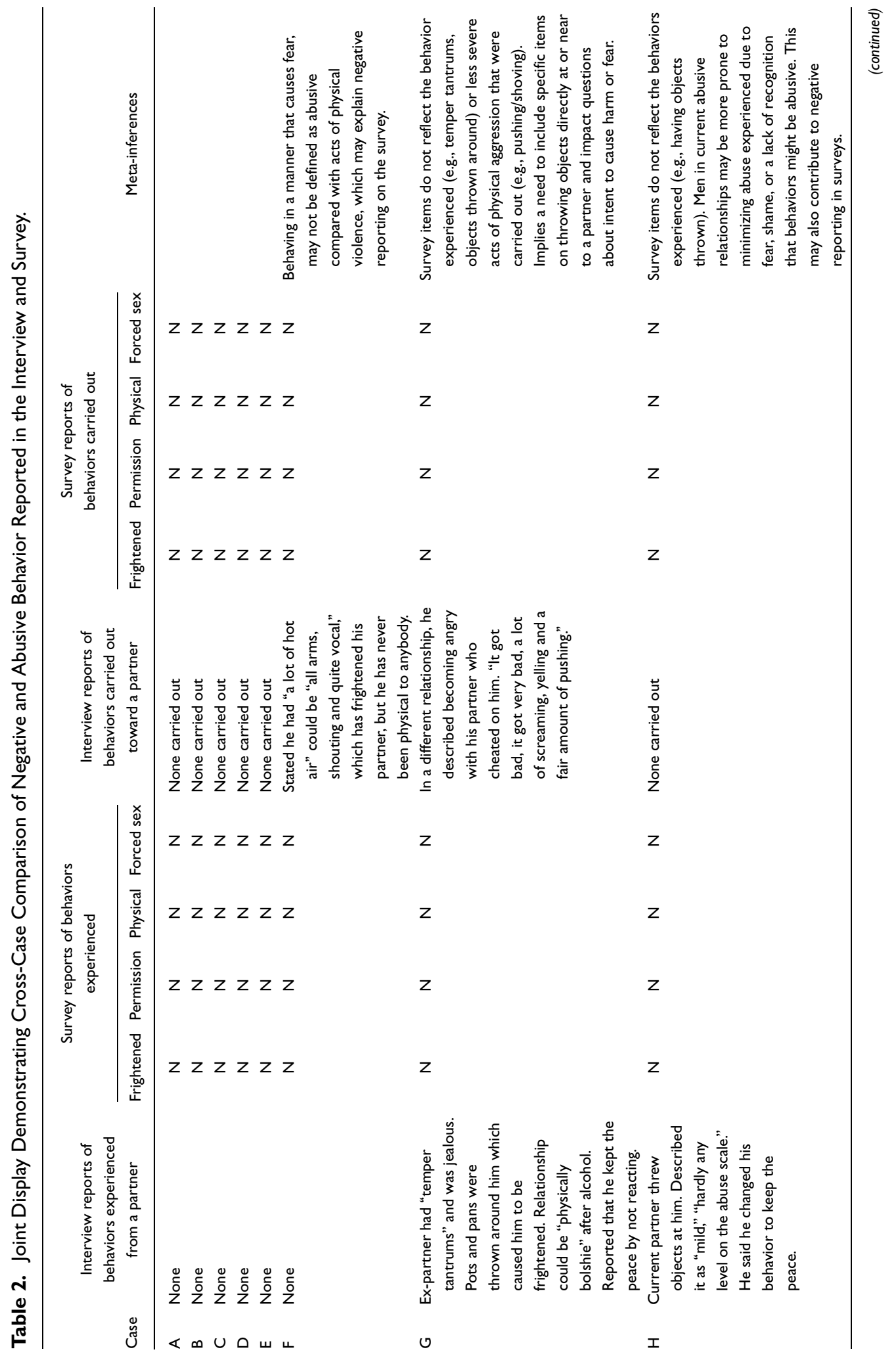




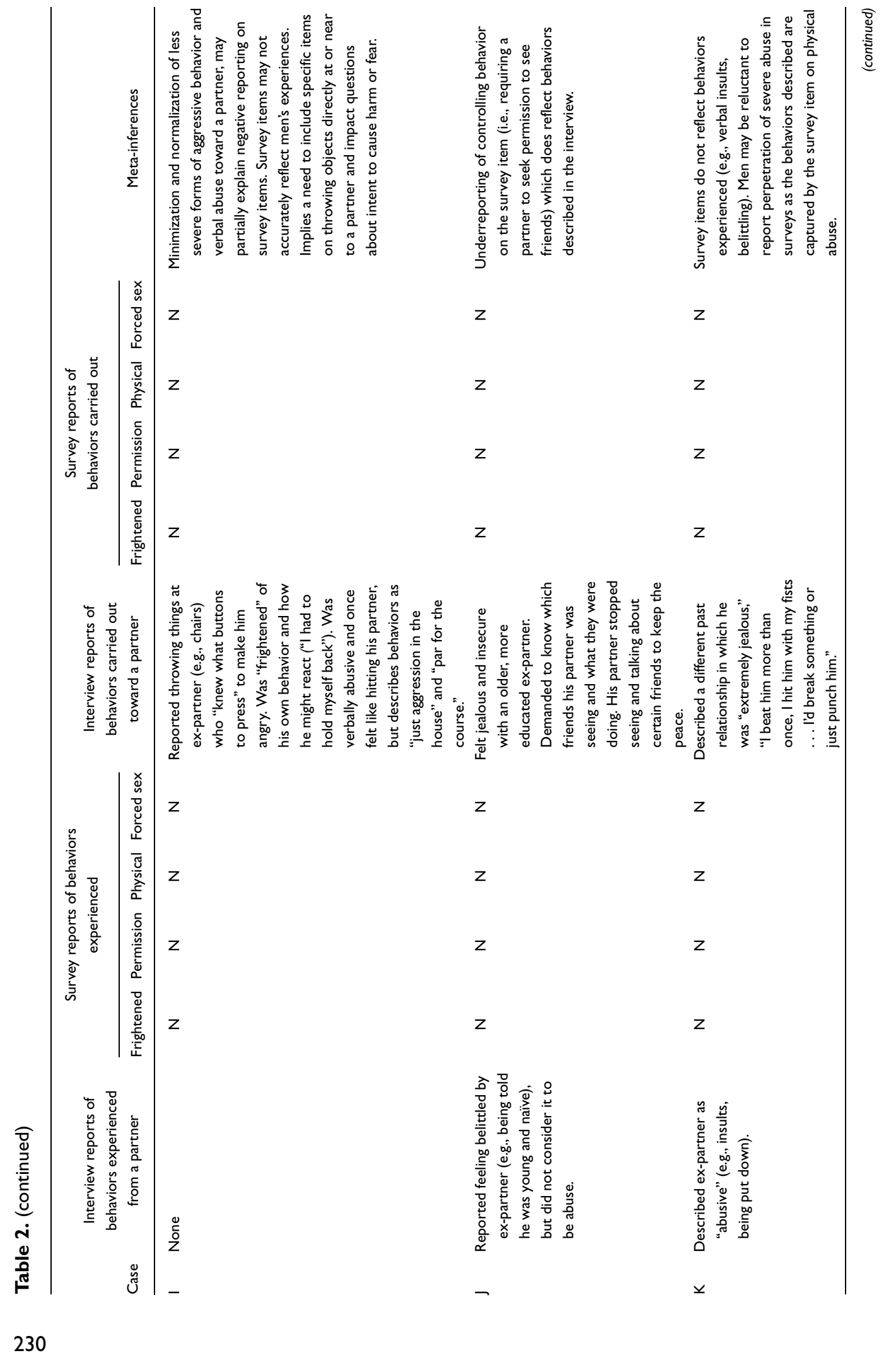




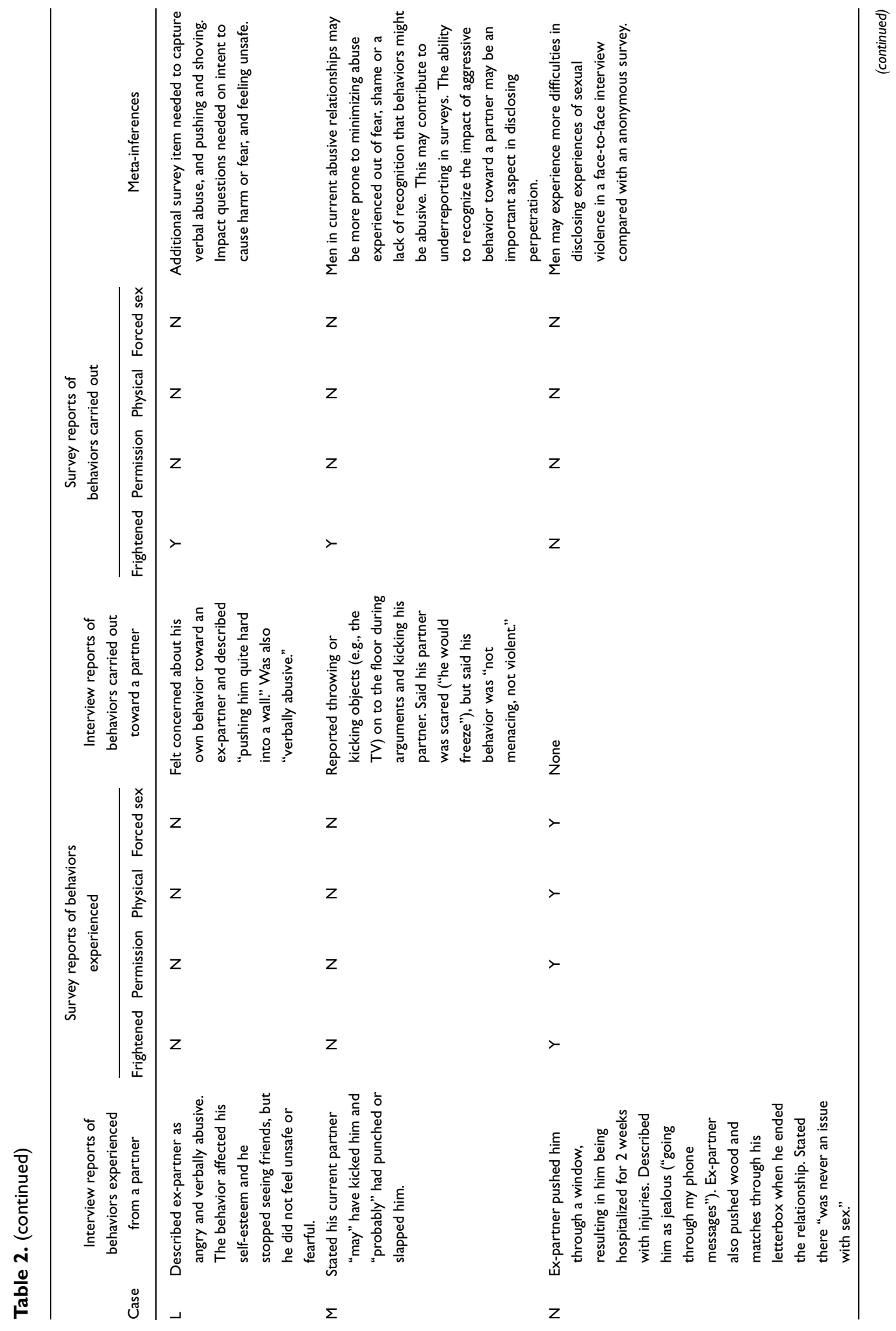




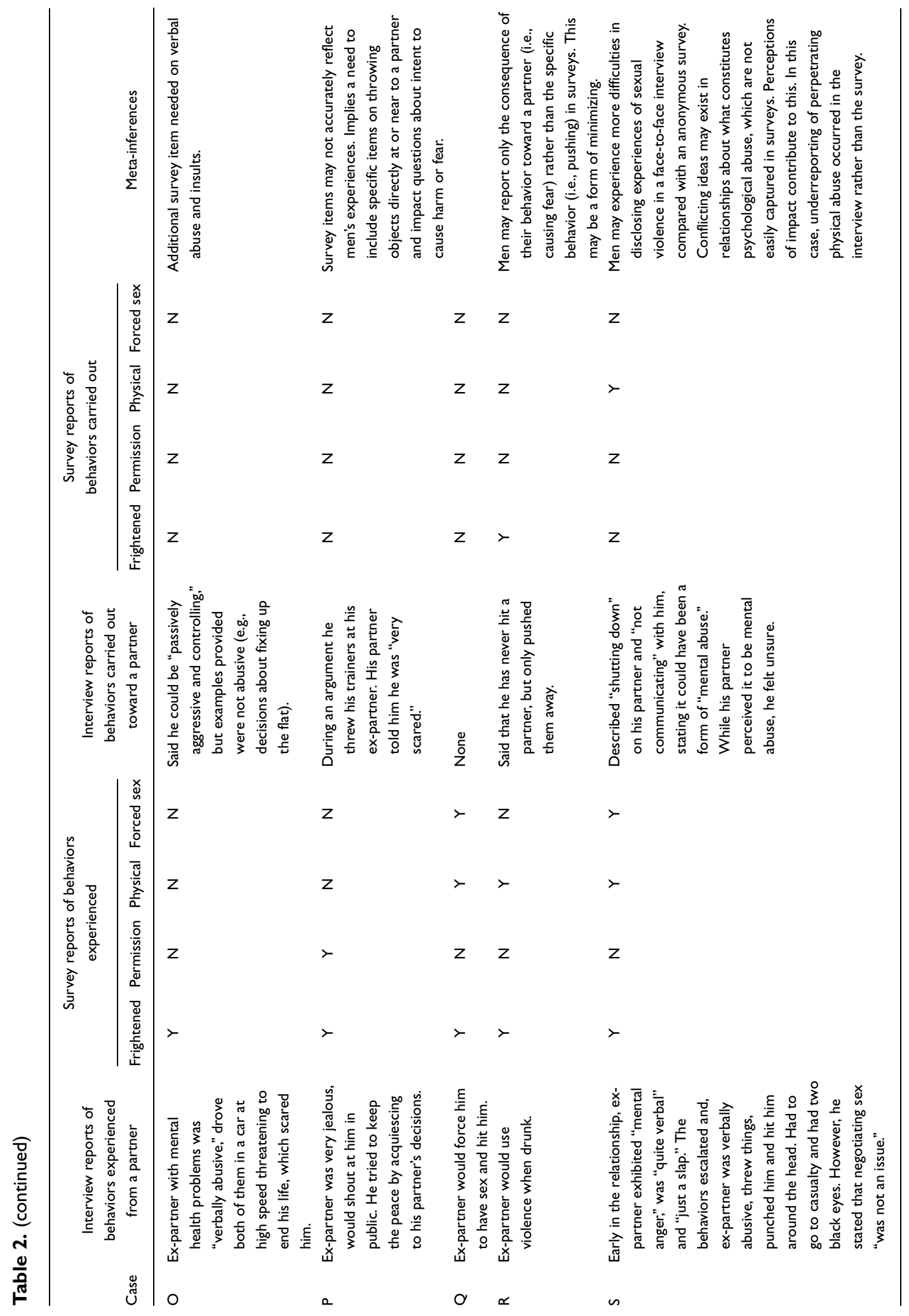


$2.4 \%$ to $5.9 \%$ ) gay and bisexual men reported ever being asked by a health professional whether they had been hurt or frightened by a partner and 9 out of $523(1.7 \% ; 95 \% \mathrm{CI}=0.7 \%$ to $2.9 \%)$ had ever been asked about perpetrating these behaviors. In terms of whether health professionals should ask patients about having ever hurt or frightened a partner, $146(28.0 \% ; 95 \% \mathrm{CI}, 24.0 \%$ to $32.2 \%)$ indicated that health professionals should ask all patients routinely, $340(65.3 \% ; 95 \%$ $\mathrm{CI}=61.0 \%$ to $69.6 \%)$ only some patients based on presenting symptoms, and $35(6.72 \%)$ stated that no patients should be asked.

The semistructured interviews help illuminate men's preferences. There was concern that routine enquiry may result in a health practitioner asking a patient about abuse in the context of a worrying or serious sexual health problem and that neglecting a patient's immediate concerns may deter them discussing abuse.

A lot of people who come here will be frightened, scared, very, very nervous and not wanting to talk about really the reasons why they are there. Especially if they think they maybe be infected with HIV . . . [discussion about domestic violence] is not necessarily going to be reasoned and coherent. They're not necessarily going to be in the best place to be listening. (Chris, 43 years)

I think it should be done on a case by case basis. I suppose possibly by the information they've kind of deduced from the patient. I think they should only do it if it's related to the kind of symptoms that the person shows. (Lewis, 21 years)

One man who preferred selective enquiry for DVA suggested that a more conversational approach might elicit honest responses, and that highlighting the connection between abuse and sexual health problems would be a way to open up communication.

Yeah, I think that a bit of an explanation along with the question would probably be more benefit and [elicit] more accurate responses. Something along the lines that "we often find that people might be susceptible to infections if they are in an abusive relationship and you could list a few possibilities. If you wanna talk about these issues we do have trained people here to discuss it with, maybe offer advice and help." (Dylan, 57 years)

Some men felt that the hectic environment of the sexual health clinic would make it challenging for sexual health practitioners to ask all patients about DVA and respond to disclosures sensitively. Creating a domestic violence-aware culture within sexual health clinics was seen as more important, for example, by having posters and leaflets available in the waiting areas or notices informing men that they could talk to a practitioner about abuse.

I don't know if the practitioner has time to ask everybody that question ... should they ask everybody? I don't think so. Some people might get upset by that question, may think "where is this coming from? Why are you asking me that?" Maybe what should be more obvious is having much more leaflets and posters in the waiting area. Maybe a poster saying if you want to discuss domestic abuse with a practitioner feel free to do so, give them that option rather than ask everybody. (Gabe, 33 years)

Choosing the right moment in the development of the patient-practitioner relationship, when trust has been established was regarded as a facilitator to disclosing abuse, and that selective enquiry for DVA would best support this process.

When I come here I just want to get the job done and go. I probably may not have met that person before, I don't want to start spluttering out all the things that have been going on. I now have a very good relationship with my HIV consultant and if he were to ask me that question, I would probably be much more open about discussing it with him. (Gabe, 33 years) 
Some felt that routine enquiry for DVA should only take place if there were properly resourced services to which men could be referred. It was also suggested that immediate on-site support might be preferable to referring men to external services.

It's very dangerous to start to explore something that you then can't support ... In an ideal world I think it would be wonderful and then I think that you would be able to refer them to a service which could see them immediately and then give them all the help they needed. The world that we live in is one of funding cuts and under resourced services. I don't think they should ask everybody, only some if it's quite obvious. (Shaun, 52 years)

It sounds a great idea, but where is the help available? Do the staff here offer help? Or maybe there are counsellors here or maybe the health advisors would be counsellors? (Dylan, 57 years)

Table 3 presents the logistic regression which examines men's views about routine enquiry for DVA (i.e., ask all patients) versus selective enquiry (i.e., ask some patients based on presenting symptoms) by health professionals in relation to different sociodemographic characteristics and abuse status. The comparator group for each independent variable is the reference category. Men who reported their ethnic group to be White were significantly less likely to support routine enquiry for DVA compared with non-White men $(32.8 \%$ vs. $47.2 \%$; odds ratio $=0.6,95 \% \mathrm{CI}=0.40-0.88)$. In the semistructured interviews there were only two non-White respondents, although both supported routine enquiry for DVA. None of the other independent variables in the regression model were significantly associated with views about routine enquiry for DVA (i.e., age, educational level, employment status, partner status, and experiences of negative behavior). Some felt that routine enquiry for DVA would reduce the potential stigma associated with selective enquiry, even if men were not ready to disclose.

If it's done in a more routine fashion, if they were asking everyone. If they were asking me, I would feel more comfortable if they were just like ... in the normal questions they ask, not like "I spot an issue with you." (Francis, 30 years)

I think it's always good to ask, but whether people give you the right answer is probably another matter. (Graham, 27 years)

In the survey, men who reported experiencing negative and potentially abusive behavior from a partner were more likely to support routine enquiry for DVA compared with those with no history of such behavior $(44.0 \%$ vs. $31.6 \%)$ although the result did not reach statistical significance. In the semistructured interviews, among those who favored routine enquiry for DVA, were two men who experienced severe acts of abuse, one of whom was pushed through a window resulting in a broken arm, and another who was raped. There was a recognition that routine enquiry was important because abuse may cause or worsen a sexual health problem. Furthermore, asking about different types of DVA would help men to label their experiences as abuse and convey a message that health professionals were willing to listen and offer support:

You've got to ask yourself why are people coming here in the first place? They might be here because they've contracted something through some sort of abuse. Yes in this environment [asking about domestic abuse] could be an added thing. (Edwin, 42 years)

Just because I couldn't say it [disclose domestic violence] doesn't mean other people might not start to see that they have a problem with their relationship. Eventually even I realised what was going on. Maybe being asked could have triggered that question in my head. (Francis, 30 years) 


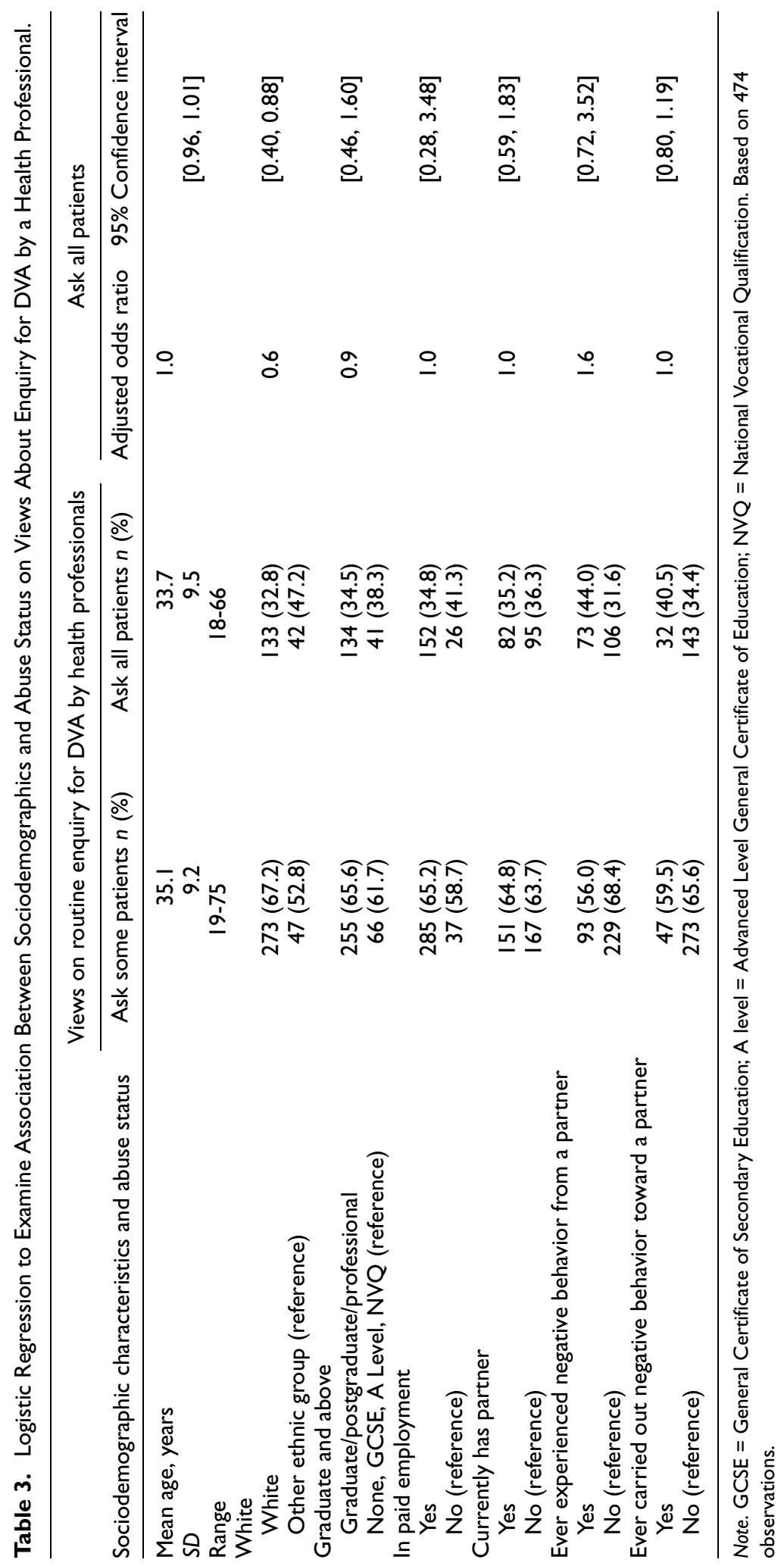




\section{The Most Appropriate Sexual Health Practitioner to Ask About DVA}

The sexual health clinic is staffed by a multidisciplinary team of doctors, nurses, and health advisors and a patient may have contact with any or all these practitioners. Therefore, it was important to elicit men's views about the most appropriate practitioner to ask about DVA. Health advisors were regarded as well placed to ask about DVA as they also provide counseling about sexual risk behaviors which also requires an empathic and nonjudgmental approach. Therefore, discussion about relationships was seen as a natural extension of their role. In comparison, doctors and nurses were viewed as working within a more medical model that was not conducive to addressing relationship issues.

Definitely a health advisor and the reason is . . I think that nurses and doctors are trained very much to a medical model and not to a health promotion model . . . Definitely health advisor cos they are much more likely to have an empathic approach. And the doctors would be like "I don't know which pill to give you for that." (Shaun, 52 years)

I'm not being disparaging with the consultants and the Special Registrars, but they're very much like "this is what you have wrong with you, we are going to do this, this and this" and if they ask [about domestic violence] in that type of tone as well, nobody is going to want to spill everything out when they have been asked everything in such a rushed way. It's not that they don't care, it comes across like that. I think that nurses are much better or even the health advisors are very good at that as well. They've got that more empathic feel to things and seem to have a bit more time to discuss these things. (Gabe, 33 years)

\section{The Most Appropriate Time to Ask About DVA}

Men were also probed for their views on the most appropriate time during their trajectory in the clinic to ask about abuse. The initial assessment was seen as an opportune time to raise the issue of DVA because questions about sexual history are asked, or alternatively during counselling sessions with health advisors. However, asking about abuse during procedures such as taking blood or providing urine samples was deemed to be inappropriate.

I'd say the initial assessment when you go in and are seen by the doctor at just the general round up. They could perhaps say "are there any potential abusive or violent episodes in your life that you might want to discuss with a professional?" . . I think that it's good at that time because they are discussing disease and being susceptible to receiving infection and that sort of thing. I suppose it comes in hand with it doesn't it? (Dylan, 57 years)

I spoke to somebody who wasn't a doctor [referring to a health advisor] who said "you're here today because you're worried that you may have picked up HIV infection so let's talk about what happened." I think that would be a good point to [ask about domestic violence] rather than the first stage where you're getting your blood taken and it's just dropped into the conversation. (Brian, 33 years)

\section{Gender of the Health Practitioner}

There were mixed views on whether gender of the health practitioner might influence men's decision to disclose abuse. Some felt more comfortable talking to female practitioners and feared that they might be judged by a male practitioner. Although the social stigma of being abused by another man was seen as a barrier to seeking help, it was ultimately the interpersonal skills of the health practitioner that were considered important regardless of gender. 
I do wonder, in a MSM relationship with the addition of testosterone, machismo is probably an even bigger social barrier to admitting as a man that you're in a relationship between men [and] that you are being abused. (Chris, 43 years)

I think it's difficult ... I feel more able to talk to a woman than a man. I always feel that if I talk to a man they're judging me and I always feel when I talk to a woman, they're not. (Lewis, 21 years)

I think a lot of gay guys are quite effeminate and they have a real attachment to women. I know lots of gay guys who do really get on well with women. I'd be happy for you to ask me and I think it depends on their approach and I suppose some people might prefer male some might women. (Ian, 43 years)

\section{Asking Men About DVA in Other Health Care Settings}

There were fairly strong views about general practitioners not having the time or skill to discuss relationship abuse. Men said that their general practitioner (GP) was unaware of their sexual orientation, which created a barrier to open communication. Sexual health clinics were seen as ideal places in which to ask about DVA because sensitive issues, including sexual orientation, are already discussed and they provide a greater sense of confidentiality:

I think [with] the GP you don't get a sense of anonymity and confidentiality. You almost think that when you see a GP that everything is written down and that's going to be on your record for a very long time. So even if that GP leaves you're still never allowed to forget your past. But whereas coming here [sexual health clinic] and speaking to the health workers here, are almost non-judgemental. (Alex, 29 years)

R: Have you ever been open about your sexuality with your GP?

P: No funnily enough, it has never come up. I've known my doctor for as long as I've lived, so 30 years, and I don't think that I have ever discussed with her anything to do with my sexuality whatsoever. I don't think I would feel comfortable talking about my sexuality whatsoever. (Omar, 29 years)

\section{Discussion}

The primary aim of this article is to illustrate the use of a case series mixed methods display for integrating interviews and survey data on gay and bisexual men's experiences of negative and abusive behavior in the context of intimate relationships. The joint display provided a visual means for displaying mutually informing qualitative and quantitative findings, which helped generate new meta-inferences that would not have been identified through separate analysis of the data components (Bazeley, 2011; Fetters et al., 2013). It revealed a tendency for men to underreport experiencing and/or carrying out negative and abusive behavior in the survey. The semistructured interviews elicited more detailed accounts of these behaviors, particularly when these were directed toward a partner, and the potential reasons for underreporting in the survey. This included a lack of recognition of the effects of their abuse toward a partner, not feeling fearful of a partner's aggressive behavior toward them, and minimizing or normalizing abusive behavior. It is also possible that men in current abusive relationships are more likely to minimize abuse experiences because of fear, shame, or not recognizing behaviors as abusive, which may also lead to underreporting in surveys. This was corroborated by the survey data, which found that the majority of men who had experienced or carried out negative and abusive behavior, did not perceive themselves to have been in a domestically violent or abusive relationship (Bacchus et al., 2017). Use of the case series display also demonstrated that the validated abuse measure did not fully capture the subjective abuse experiences of men. Some of the abusive behaviors described by men in the interviews were not accurately reflected in the four survey 
items. Common behaviors identified in the interviews include the use of verbal abuse, belittling, pushing, and throwing objects at or near a partner. Integration of the quantitative and qualitative findings regarding abuse highlighted the difficulty of reducing complex behaviors within an intimate relationship to a small number of checklist items (Testa, VanZile-Tamsen, Livingstone, \& Koss, 2004). However, the anonymous survey may have been better for eliciting disclosures of forced sex than the interview. Men's subjective definitions about what constitutes abusive behavior were sometimes very different to those captured by the survey items. Additional questions on the perceived impact of abusive acts and intent to cause fear or harm are needed to contextualize behaviors.

Evans, Gregory, Howarth, Hegarty, and Feder (2016) also highlighted the limitations of using single methods for exploring abuse experiences among women. Cognitive and qualitative interviewing was conducted with abused women who also completed the Composite Abuse Scale, a validated multidimensional measure of the frequency and severity of abuse. Their study also found underreporting of abuse on the scale, particularly with regard to coercive control, threatening behavior, restrictions to freedom and sexual abuse. This related to interpretation of abuse items and response choices, fear of answering truthfully, and an unwillingness to identify with certain types of abuse. There is a need to augment quantitative approaches to the study of DVA with qualitative enquiry, to better understand the complexity of the phenomenon, and assist with interpretation.

In the survey, $11 \%$ of men reported both experiencing and carrying out negative behavior which suggests that knowledge of services for victims and perpetrators is necessary among health care practitioners. It is important for health practitioners to understand that a wide range of mild-to-severe acts of violence and situations of unilateral and bidirectional DVA can occur in gay men (Stanley, Bartholomew, Taylor, Oram, \& Landolt, 2006). Orliffe et al. (2014) suggest that gay men not only normalize violence as being characteristic of a close and turbulent relationship, but also normalize and conceal physical and mental injuries as part of being a strong man who can withstand the abuse. Furthermore, the discourse around masculine aggression used to rationalize mutual aggression obscures the boundary between victim and perpetrator, which creates a barrier to men seeking help from victim support services. In our interviews, all men interpreted the open-ended question on views of routine enquiry for DVA in the context of victimization experiences and none offered views on enquiry for perpetration. Further research is needed to explore how enquiry for DVA might incorporate both victimization and perpetration experiences.

With regard to our secondary aim, the use of a mixed methods approach enhanced our understanding of gay and bisexual men's preferences for support from health practitioners in relation to enquiry for DVA. This generated new knowledge, which has important implications for public health and clinical policy, contributing to the evidence base needed to develop an effective health care response to male patients who experience or perpetrate DVA. Integration of quantitative and qualitative data at the level of reporting and interpretation helped contextualize men's preference for selective enquiry for DVA.

Although the survey found that very few men had ever been asked about DVA by a health practitioner, the majority supported the practice of health practitioners asking about relationship abuse. The interviews clarified the conditions that would best facilitate interventions in sexual health service and the reasons underpinning men's preferred method of enquiry. Important contextual factors were identified such as the most appropriate time to ask about abuse during consultations, the most appropriate practitioner to ask, as well as how to initiate a conversation about partner abuse and ask questions sensitively. A third of men in the survey supported routine enquiry for DVA, while two thirds preferred selective enquiry (i.e., asking in the context of symptoms or conditions that are consistent with experiences of DVA). Support for the practice 
of routine enquiry about DVA in our sample of gay and bisexual men is lower compared with studies eliciting women's views (Feder et al., 2009). However, the results are comparable to a general practice survey of heterosexual men's views of enquiry for DVA by health practitioners in which $65 \%$ of men supported selective enquiry (Morgan et al., 2014). Possible reasons include prior negative experiences with formal organizations, which can play a significant role in gay and bisexual men's decision to remain silent about abuse, homophobic discrimination, and fears that disclosure will result in them being “outed"' (Donovan \& Hester, 2006). Men's preference for selective enquiry for DVA can also be understood within the social construction of masculinities, which discourage men from talking about emotional problems (Gascoigne \& Whitear, 1999; Moynihan, 1998).

Sexual health clinics were regarded as favorable settings in which to discuss DVA with gay and bisexual men. Men regularly attend for checkups as well as for symptom-related visits and health practitioners are accustomed to discussing sensitive issues including sexual risk behaviors. However, men in long-term relationships may not access sexual health services frequently, thereby reducing opportunities for them to seek help for partner abuse. Health advisors were identified as the best placed practitioners to ask about DVA because they provide counseling in relation to risk behaviors such as unsafe sex, alcohol and substance abuse, and depression, all of which can co-occur with DVA (Buller, Devries, et al., 2014). Furthermore, they have time to develop a trusting relationship with patients, which can facilitate disclosure of abuse, a finding which has been reported in a Canadian study of a screening protocol for intimate partner violence in a HIV clinic (Raissi, Krentz, Siemieniuk, \& Gill, 2015).

Men felt that enquiry for DVA should not take place without available resources, which could potentially be provided by the clinic. For example, having a link to a local DVA organization with an identified advocate for the clinic, a model that has been successfully used in U.K. general practice settings with women affected by DVA (Feder et al., 2011) and in a U.S. community health center for LGBT people (Basham, King, Presley-Kimball, \& Potter, 2015). Alternatively, health advisors can be skilled-up to be the initial point of referral and link to other services. Within the health setting, this may require referral to mental health or drug and alcohol teams, HIV services, or sexual assault referral centers. Outside the health setting, staff with additional DVA training should have knowledge of local and national organizations that offer support to LGBT people who are experiencing and/or perpetrating DVA. Displaying posters and leaflets in clinic waiting rooms will promote the message that health practitioners view DVA as a health issue and are able to support.

Health services need to commission training for health practitioners to increase their awareness of DVA that occurs in the LGBT community and the specific challenges they encounter when seeking help. Training should also support health practitioners in developing communication skills and client trust that enable them to make sensitive enquiries when they suspect that a patient may be abused. The majority of tools that are currently used to assess for DVA have been developed for use with heterosexual women. Stephenson, Hall, Williams, Sato, and Finneran (2013) developed a six-item tool for gay and bisexual men and recommend that its acceptability and feasibility be tested in health care settings. In our study, a pilot training intervention for sexual health practitioners was implemented in the LGBT clinic to promote identification, documentation, and referral of male patients experiencing or perpetrating DVA. As a result of the training, practitioners reported increased awareness of the issue and confidence in asking men about abuse (Buller, Bacchus, Brzank, \& Feder, 2014).

Our study has a number of limitations and the findings should be interpreted within the context of this particular sexual health service. It was not possible to sample purposively for the semistructured interviews, which may have generated a more diverse group of men in relation to severity of abuse, victimization, perpetration, and sociodemographic characteristics. 
Additionally, the study may have excluded gay and bisexual men in long-term relationships who do not make frequent use of sexual health services, whose views may have differed to those presented. The semistructured interviews were conducted by female researchers and male researchers may have elicited qualitatively different data. However, given men's views about feeling more comfortable discussing DVA with female health practitioners, it is possible that the use of female researchers enhanced the quality of the data. Last, integration of qualitative and quantitative findings regarding abuse experiences suggest that the survey results are most likely an underestimate of the occurrence of DVA.

Integration in mixed methods research can be challenging and careful planning is necessary to determine how it can be used at various stages of the research process to achieve greater leverage (Fetters \& Freshwater, 2013). We propose that further mixed methods research is needed to develop and test gender-sensitive interventions for gay men that move beyond heteronormative discourses of victim and perpetrator and reflect gay men's constructions of their relationships and of DVA.

\section{Authors' Note}

The study was approved by the South West Ethics Committee (reference: 10/H0106/22).

\section{Acknowledgments}

The authors wish to thank Broken Rainbow, Stonewall Housing, and GALOP for their contributions to the development of the research instruments.

\section{Declaration of Conflicting Interests}

The author(s) declared no potential conflicts of interest with respect to the research, authorship, and/or publication of this article.

\section{Funding}

The author(s) disclosed receipt of the following financial support for the research, authorship, and/or publication of this article: This article presents independent research commissioned by the National Institute for Health Research (NIHR) under its Programme Grants for Applied Research scheme (RP-PG-0108-10084). The views expressed in this publication are those of the author(s) and not necessarily those of the NHS, the NIHR, or the Department of Health.

\section{References}

Bacchus, L. J., Buller, A. M., Ferrari, G., Peters, T. J., Devries, K., Sethi, G., . . Feder, G. S. (2017). Occurrence and impact of domestic violence and abuse in gay and bisexual men: A cross-sectional survey. International Journal of STD and AIDS, 28:16-27. doi:10.1177/0956462415622886

Ball, M. J. (2011). Gay men, intimate partner violence and help-seeking: The incomprehensibility of being a victim. In B. Scherer \& M. J. Ball (Eds.), Queering paradigms II: Interrogating agendas (pp. 313330). New York, NY: Peter Lang.

Basham, C., King, D., Presley-Kimball, C., \& Potter, J. (2015, November 19). Implementing routine interpartner violence screening at a LGBT health center. Paper presented at the 38th Annual Meeting of the Society of General Internal Medicine, Toronto, Ontario, Canada.

Bazeley, P. (2011). Integrative analysis strategies for mixed data sources. American Behavioral Science, $56,814-828$.

Buller, A. M., Bacchus, L. J., Brzank, P., \& Feder, G. (2014). A pilot of an educational and support intervention targeted at sexual health practitioners to promote enquiry about experience or 
perpetration of $D V$ and improved management after disclosure. Retrieved from http://www.bris.ac.uk/ social-community-medicine/projects/provide/workstream-3/

Buller, A. M., Devries, K. M., Howard, L. M., \& Bacchus, L. J. (2014). Associations between intimate partner violence and health among men who have sex with men: A systematic review and metaanalysis. PLoS Medicine, 11(3):e1001609. doi:10.1371/journal.pmed.1001609

Denscombe, M. (2008). Communities of practice. A research paradigm for the mixed methods approach. Journal of Mixed Methods Research, 2(3), 270-283.

Dickson, V. V., Lee, C. S., \& Riegel, B. (2011). How do cognitive function and knowledge affect heart failure self-care? Journal of Mixed Methods Research, 5(2), 167-189.

Donovan, C., \& Hester, M. (2010). "I hate the word "victim": An exploration of recognition of domestic violence in same sex relationships. Social Policy \& Society, 9, 279-289.

Donovan, C., \& Hester, M. (2015). Domestic violence and sexuality: What's love got to do with it? Bristol, England: Policy Press.

Donovan, C., Hester, M., Holmes, J., \& McCarry, M. (2006). Comparing domestic abuse in same sex and heterosexual relationships. Bristol, England: University of Bristol.

Duke, A., \& Davidson, M. M. (2009). Intimate partner violence research. Same-same intimate partner violence: Lesbian, gay and bisexual affirmative outreach and advocacy. Journal of Aggression, Maltreatment \& Trauma, 18, 795-816.

Evans, M., Gregory, A., Howarth, E., Hegarty, K., \& Feder, G. (2016) “Even 'daily' is not enough": How well do we measure domestic violence and abuse? A think-aloud study of a commonly use self-report scale. Violence and Victims, 31, 3-26. doi:10.1891/0886-6708.VV-D-15-00024

Feder, G., Agnew Davies, R., Baird, K., Dunne, D., Eldridge, S., Griffiths, C., . . . Sharp, D. (2011). Identification and Referral to Improve Safety (IRIS) of women experiencing domestic violence with primary care training and support programme: A cluster randomised controlled trial. Lancet, 378, 1788-1795.

Feder, G., Ramsay, J., Dunne, D., Rose, M., Arsene, C., Norman, R., . . Taket, A. (2009). How far does screening women for domestic (partner) violence in different health care settings meet the UK National Screening Committee criteria for a screening programme? Systematic reviews of nine UK National Screening Committee criteria. Health Technology Assessment, 13(16), iii-iv, xi-xiii, 1-113, 137-347. doi: $10.3310 /$ hta 13160

Feder, G. S., Hutson, M., Ramsay, J., \& Taket, A. R. (2006). Women exposed to intimate partner violence. Expectations and experiences when they encounter health care professionals. A meta-analysis of qualitative studies. Archives of Internal Medicine, 166, 22-37.

Fetters, M. D., Curry, L. A., \& Creswell, J. W. (2013). Achieving integration in mixed methods designs. Principles and practice. Health Services Research, 48, 2134-2156.

Fetters, M. D., \& Freshwater, D. (2015). The 1+1=3 integration challenge. Journal of Mixed Methods Research, 9(2), 115-117.

Finneran, C., \& Stephenson, R. (2013). Intimate partner violence among men who have sex with men. A systematic review. Trauma, Violence, \& Abuse, 14, 168-185.

Flick, U. (2014). An introduction to qualitative research (5th ed.). London, England: Sage.

Freedburg, P. (2006). Health care barriers and same sex intimate partner violence: A review of the literature. Journal of Forensic Nursing, 2, 15-24.

Galdas, P. M., Cheater, F., \& Marshall, P. (2005). Men and health help-seeking behaviour: Literature review. Journal of Advanced Nursing, 49, 616-623.

Gascoigne, P., \& Whitear, B. (1999). Making sense of testicular cancer symptoms: A qualitative study of the way in which men sought help from the health care services. European Journal of Oncology Nursing, 3, 62-69.

Guetterman, T. C., Fetters, M. D., \& Creswell, J. W. (2015). Integrating quantitative and qualitative results in health science mixed methods research through joint displays. Annals of Family Medicine, $13,554-560$.

Haggerty, J. L., Roberge, D., Freeman, G. K., Beaulieu, C., \& Breton, M. (2012). Validation of a generic measure of continuity of care: When patients encounter several physicians. Annals of Family Medicine, $10,443-451$. 
Hester, M., Fahmy, E., \& Donovan C. (2010). Feminist epistemology and the politics of method: Surveying same sex domestic violence. International Journal of Social Research Methodology, 13, 251-263.

Hearn, J. (2013). The sociological significance of domestic violence: Tensions, paradoxes and implications. Current Sociology, 61, 152-170.

Hester, M., Ferrari, G., Jones, S. K., Williamson, E., Bacchus, L. J., Peters, T. J., \& Feder, G. (2015). Occurrence and impact of negative behaviour, including domestic violence and abuse in men attending UK primary care health clinics: A cross sectional survey. BMJ Open, 5(5), e007141. doi: 10.1136/bmjopen-2014-007141

Kaschak, E. (2001). Intimate betrayal: Domestic violence in lesbian relationship. Women and Therapy, 23(3), 1-5.

Miles, M. B., \& Huberman, M. (1994). Qualitative data analysis: A sourcebook of new methods (2nd ed.). Thousand Oaks, CA: Sage.

Möller-Leimkühler, A. M. (2002). Barriers to help-seeking by men: A review of sociocultural and clinical literature with particular reference to depression. Journal of Affective Disorders, 71, 1-9.

Morgan, K., Williamson, E., Hester, M., Jones, S., \& Feder, G. (2014). Asking men about domestic violence and abuse in a family medicine context: Help seeking and views on the general practitioner role. Aggression and Violent Behavior, 19, 637-642.

Moyer, V. A. (2013). Screening for intimate partner violence and abuse of elderly and vulnerable adults: A U.S. Preventive Services Task Force Recommendation Statement. Annals of Internal Medicine, 158, 478-486.

Moynihan, C. (1998). Theories in health care and research: Theories of masculinity. British Medical Journal, 317, 1072-1075.

National Institute for Health Care and Excellence. (2014). Domestic violence and abuse: How health services, social care and the organisations they work with can respond effectively. (NICE Public Health Guidance 50). London, England: Author.

O'Cathain, A., Murphy, E., \& Nicholl, J. (2008). The quality of mixed methods research in health services research. Journal of Health Services Research \& Policy, 13, 92-98.

O’Doherty, L. J., Taft, A., Hegarty, K., Ramsay, J., Davidson, L. L., \& Feder, G. (2014). Screening women for intimate partner violence in healthcare settings: Abridged Cochrane systematic review and metaanalysis. BMJ Open Access, 348, g2913. doi:10.1136/bmj.g291

Oliffe, J. L., Han, C., Estephanie Sta. Maria., Lohan, M., Howard, T., Stewart, D. E., MacMillan, H. (2014). Gay men and intimate partner violence: A gender analysis. Sociology of Health and Illness, 36, 564-579.

Public Health England. (2015). PHE action plan 2015-16. Promoting the health and wellbeing of gay, bisexual and other men who have sex with men. London, England: Author.

Raissi, S. E., Krentz, H. B., Siemieniuk, R. A. C., \& Gill, M. J. (2015). Implementing an intimate partner violence (IPV) screening protocol in HIV care. AIDS Patient Care and STDs, 29, 133-141.

Saunders, J. B., Aasland, O. G., Babor, T. F., de la Fuente, J. R., \& Grant, M. (1993). Development of the Alcohol Use Disorders Identification Test (AUDIT): WHO Collaborative Project on Early Detection of Persons with Harmful Alcohol Consumption-II. Addiction, 88, 791-804.

Spector, A. Y., \& Pinto, R. M. (2011). Let's talk about sex: Helping substance abuse counsellors address HIV prevention with men who have sex with men. Culture, Health \& Sexuality, 13, 399-413.

Spector, A. Y., Pinto, R. M., Rahman, R., \& de Fonseca, A. (2015). Implementation of Brazil's "family health strategy": Factors associated with community health workers', nurses' and physicians' delivery of drug use services. International Journal of Drug Policy, 26, 509-515.

Stanley, J. L., Bartholomew, K., Taylor, T., Oram, D., \& Landolt, M. (2006). Intimate violence in male same-sex relationships, Journal of Family Violence, 21, 31-41.

Stephenson, R., Hall, C. D., Williams, W., Sato, K., \& Finneran, C. (2013). Towards the development of an intimate partner violence screening tool for gay and bisexual men. Western Journal of Emergency Medicine, 14, 390-400.

Teddlie, C., \& Tashakkori, A. (2009). Foundations of mixed methods research. Integrating quantitative and qualitative approaches in the social and behavioural sciences. London, England: Sage. 
Testa, M., VanZile-Tamsen, C., Livingston, J. A., \& Koss, M. P. (2004). Assessing women's experiences of sexual aggression using the sexual experiences survey: Evidence for validity and implications for research. Psychology of Women Quarterly, 28, 256-265.

World Health Organization. (2013). Responding to intimate partner violence and sexual violence against women. WHO clinical and policy guidelines. Geneva: WHO.

Williamson, E., Agnew-Davies, R., Bacchus, L. J., Buller, A. M., Hester, M., Howard, L. M., . . Feder, G. (2014). Developing the PROVIDE measure of potentially abusive behaviours. Bristol, England: University of Bristol.

Zigmond, A. S., \& Snaith, R. P. (1983). The hospital anxiety and depression scale. Acta Psychiatrica Scandinavica, 67, 361-370. 